\title{
A Reflection on the First Run of the Runestone Project at Tongji University: Observations on Cross Cultural Distributed Teams vs Face to Face Teams
}

\author{
MinJuan Janet Tong \\ SERL, School of Computing \& Mathematical Sciences \\ Auckland University of Technology \\ Auckland, New Zealand \\ mtong@aut.ac.nz
}

\author{
Tony Clear \\ School of Computing \& Mathematical Sciences \\ Auckland University of Technology \\ Auckland, New Zealand \\ Tony.clear@aut.ac.nz
}

\begin{abstract}
China has long been an education import nation, so non-commercial and mutually beneficial collaborations between Chinese and Western universities are rare. Nevertheless, the School of Software Engineering at Tongji University in China has developed mutually beneficial collaboration with several Western universities; among them the most important partner is Uppsala University. In spite of the great challenges encountered by both sides during developing and conducting the collaboration due to their sharply contrasting cultural backgrounds and different educational and political systems, the collaboration between the institutions has been deepening and widening steadily and continuously. Following successful student and teacher exchange programs, the Runestone project was launched between Uppsala and Tongji Universities in 2009. It was taken as a triumph that the Sino-Swedish globally distributed Runestone teams fulfilled the course requirements. However, it was also noticed that some advantages of cross cultural collaboration in learning which were observed in the face to face teams were not realized in the SinoSwedish Runestone teams. The students in the cross cultural face to face teams displayed evident complementarities in their work. This positive effect of the different cultural backgrounds seemingly disappeared when the students moved from the face to face teams to the globally distributed teams. This report records observations on students' work in the two types of cross cultural teams. In addition, on the basis of these reflections on the experience, some practical measures and areas for research are suggested in the hope of helping improve such global collaborations in future.
\end{abstract}

Keywords- Runestone project; face to face team; globally distributed team; cross cultural collaboration; global software engineering

\section{INTRODUCTION}

Due to the rapid development of globalization in the software engineering industry, working in globally distributed and cross cultural environments has become an increasingly demanded professional skill. Accordingly, Western software engineering educators have put immense efforts into helping students develop such skill by including cross cultural teamwork into curricula [1]. Some collaborative courses which provide students the chance to work in cross cultural and globally distributed teams (GDT) have been initiated and are being refined at Western universities. The Runestone project is such a course initiated and hosted by Uppsala University.

Chinese students majoring in software engineering are particularly expected to have the skill of working in cross cultural GDTs because of the blooming of outsourced software engineering in Western countries [2]. However, no course in the nature of Runestone has been developed by Chinese educators. Therefore, the Runestone project provides the students from the School of Software Engineering at Tongji University in China (SSE) a unique chance to work in GDTs. Although the Sino-Swedish members in the first run of Runestone project were considered to be doing well, it was also noticed that that the advantages of the cross cultural collaboration in learning displayed in the previous face to face teams seemingly became lost in the Sino-Swedish Runestone teams.

We believe that understanding the special challenges encountered by the Sino-Swedish students in the Runestone teams is the starting point of helping the future students to improve their collaboration in the Sino-Swedish Runestone teams. For this reason, on the basis of the observations obtained in the cross cultural face to face and the Sino-Swedish Runestone teams, we present these reflections as an attempt to understand and deal with the challenges.

The rest of this report is organized into four sections. First, the background of SSE is examined, and the Runestone project is briefly introduced. Second, observations on the cross cultural face to face teams and the first run of the Sino-Swedish Runstone project are presented. This is followed by the reflections on the observations. The report ends with the conclusion in which some practical measures and research topics are suggested in the hope of helping both students and educators to improve their collaboration in the future Runestone course and similar globally distributed courses in other contexts.

\section{BACKGROUND}

\section{A. The Background of SSE}

It is difficult to launch and operate reciprocally beneficial collaboration in Chinese tertiary institutions, mainly because 
the Chinese education system was isolated from the rest of the world from 1949 to 1978 [3]. The isolation created serious language barriers, unsuitable curricula and teaching approaches for establishing mutually beneficiary collaboration.

In 2001, China's Ministry of Education and China's Committee of Development and Reformation determined to establish some pilot institutions of software engineering at the first class Chinese universities. The aim was educating international level software engineers. These institutions were granted certain freedoms in hiring faculty, developing novel curricula, and encouraged to develop collaborations with foreign universities and software companies [4]. Under this authorization, SSE was established in 2002 among 34 other peer institutions.

Enjoying the limited freedom, SSE hired people who could teach in English and developed the courses by collaborating with famous international software companies. These elements turned out to be the foundation of developing reciprocally beneficial collaborations at SSE.

As a newly founded school, SSE had been striving for gaining its prominent status among those long established schools at Tongji and distinguishing itself from its peer pilot institutions at other universities. While other pilot schools tried to make their fame by importing education programs, SSE managed to stand as the fifth in the rank of the pilot software engineering institutions by developing its non-profit and reciprocally beneficial collaborations. The most valuable and fruitful collaborations are the programs established with Uppsala University (UU). The Runestone project between Tongji and Uppsala was launched in 2009, following the student exchange program (2005) and the teaching exchange program (2008).

To prepare its students for being practical and effective professionals, SSE encourages the students to work in a manner of "learning by doing". Starting from the second year, in every course the SSE students are required to complete a term project from scratch in teams. The assessments are based on their products from these projects. The students are allowed to choose the themes of the projects and their partners in the teams.

The Western exchange students studying on site at SSE participate in the teams for term projects. SSE students and Western students work through the project through the term. This kind of team is called the 'cross cultural face to face team' in this report. It has been witnessed that SSE students developed their communication skills and social ease in these face to face cross cultural teams. In addition, SSE and Western members in these face to face teams, and their instructors noticed that complementarities between SSE and Western students' abilities enhanced their working performances and qualities.

\section{B. Runestone Project}

The Runestone project was initiated and has been hosted at Uppsala University in Sweden. It is a collaborative course which is offered between Uppsala University and its partner universities.
It was designed as an open ended project course to allow the students to acquire important global engineering and software engineering skills [5]. The participants in the project are required to develop a software system to control a remote LEGO NXT robot in globally distributed teams, and the duration of the project is 10-12 weeks. The analysis and design of the system consists of basic and challenging parts. The latter involves identifying two areas of technical excellence for the system.

The participants are divided into teams. Each team consists of 6-7 members, half located at Uppsala University, and the rest at a partner university. The two sub-teams communicate with each other mainly by having regular sessions through Internet Relay Chat (IRC). The supplementary communication means includes e-mail, wiki, SVN and other e-communication facilities which the students may choose according to their preferences. Each team is instructed by one instructor from either Uppsala or its partner university.

In the Spring Semester in 2009, 16 students from SSE participated in the first run of the Runestone project, working in 5 teams. All the teams passed the course. The majority of SSE students participating in Runestone had experiences of working with Western students in face to face teams, and some of them had studied at Uppsala University as exchange students. Only a few students had no cross cultural working experience.

\section{OBSERVATIONS}

Last et al [6] investigated the obstacles encountered by the students in the Runstone project offered between UU and Grand Valley State University in US (GVSU) in 1999. These obstacles were listed in order of decreasing importance as follows: poor communication, member nonparticipation, poor leadership, lack of technical skills, procrastination, and differences in motivation. The above mentioned aspects of teamwork are used to organize the observations made in the cross cultural face to face teams and the Sino-Swedish teams in the first run of the Runestone project at Tongji. In addition, the observations made here on the Sino-Swedish Runestone teams are compared with those on the mentioned UU- GVSU Runestone teams.

The observations on the face to face teams were made in several courses, and they were very similar. On the other hand, the observations made in the Sino-Swedish Runestone teams varied from team to team. Three typical teams are chosen for discussion and denoted as Team A, Team B and Team C. The backgrounds of the Chinese members of these teams are different.

Team A had members who were academically strong, spoke very good English, and were highly experienced in cross cultural collaboration. Team B had members who were very fond of programming, spoke good English, and had cross cultural collaboration experience. Team $\mathbf{C}$ had members who didn't display any particular academic interests. Two of the three members spoke good English and were experienced in cross cultural collaboration. The remaining one had no experience in cross cultural collaboration and his English was not strong 


\section{A. Observations on Face to Face and Runestone Teams}

\section{1) Communication}

Face to face teams: Both Chinese and Western students admitted that communication demanded certain efforts. They developed some strategies to make communication easier: repeating, slowing down speaking, making diagrams or graphics while talking. In addition, all decisions and proposals were always posted to everybody by e-mail so that no misunderstanding occurred. In spite of the above difficulties, Western students were more interactive with the instructor of the course, asking questions or discussing their design.

Runestone teams: All of the teams mainly relied on IRC to make decisions through synchronous text message exchange. All of the SSE students complained about bad communication conditions. Confusions were caused in sessions by the delayed responses. Sometimes the sessions were forced to be ended earlier due to unreliable communication conditions. 8 hour different time zones made the meeting schedule difficult, and the meeting time was usually inconvenient for UU and SSE students.

Team A had strong habits of sharing information in a concise and timely manner. The members set up the necessary communication facility at the very beginning. All information was immediately posted or updated. Besides, they made strict schedules for their sessions. The sub-teams met before sessions. The topics to be discussed in sessions were listed and posted by e-mail to members. During the session, a meeting monitor kept the discussion sticking to the pre-defined topics. Their sessions were long and intensive but the frequency wasn't high. Team B was concerned about information sharing and discussed a lot around this issue. Compared with Team A, they took a longer time to set up the communication facility. The team had high frequency of sessions but the sessions were short, and the topics of discussions randomly drifted. Team C didn't display concern about sharing information. They took the longest time to set up communication facility. Not every member attended sessions. The members became confused about their work distributions.

Compared with SSE students, UU students were more concerned about the instructors' opinions on their work. When the instructor(s) was from SSE, they would repeatedly urge the SSE students to contact the instructor.

\section{2) Membership}

Face to face teams: Students usually formed their teams by self selection. As an exception, in a well introduced course they were arbitrarily assigned into teams. The students didn't complain about this arrangement. UU and SSE students thought they learned a lot from each other, and they also considered their partners very nice. The Chinese students believed that the members were more involved in the face to face teams. Loafing and procrastination were avoided.

Runetone teams: SSE students complained about not being allowed to choose their SSE partners.

Team A displayed a strong sense of responsibilities and strictness in following the set rules. The discussion was rare at the beginning. Whenever a disagreement occurred, the team voted for the decision. No loafing occurred. Team B had the most cheerful and friendly atmosphere among the members. Two sides showed respect toward each other and discussed a lot. Everybody was willingly to contribute to the work. Team C had a weak sense of membership. The UU students thought it wasn't necessary for every member to attend sessions. Later, two SSE students loafed because they went to their internships and failed to setup communication though they voluntarily took the duty. Only one SSE student stayed in the team. This student sometimes got confused about his duty. The majority of work was done by the wiki manager of the team.

No over participation was observed.

\section{3) Leadership}

Face to Face Teams: the SSE students normally asked a Western exchange student in the team to be their team leader as a courtesy. Some mature Western exchange students rejected the offer because they didn't think they understood Chinese students enough to be their leader. Some Western students took the leadership. Both SSE and Western students took the role of a leader as administrating and maintaining the team. Western student leaders thought that it was easy to be a leader.

Runestone teams: All team leaders of the Sino-Swedish teams were UU students. In addition, the concept of the team leader was different from what is in the face to face team.

Team A and Team B understood the team leader role as a communicator. A team leaders' duty was mainly defined as reporting the team's work to the instructor and making sure all information was well shared by every member. According to the emerging needs in communication, such as encouraging effective discussion and so on, the students set up the roles of meeting monitor, informer, and report maker. Team C understood the team leader as an administrator. The leaders of Team A and Team B worked well. The leader of Team C didn't work well, and was confused about the information such as the distribution of work.

\section{4) Technological issues}

Face to Face Teams: It was admitted by SSE and Western students and the instructors that Chinese students were good at solving technical problems and Swedish students were strong in design and information searching. Both SSE and Western students thought that they formed good counterparts. Nobody was worried about the insufficiency of knowledge.

Runestone Teams: The SSE students remarked that they didn't get sufficient training in Java programming, jumping into J2EE in the third year without learning J2SE. In the Runestone project, J2SE was the most suitable platform for implementing the system. Swedish students suggested using J2SE, and SSE students agreed but without self-confidence.

The members presented different levels of knowledge of communication facilities. In Team A, the UU students were experienced in using all communication facilities provided by UU. The SSE students had good knowledge of popular communication facilities but only had minimum knowledge about the communication facilities provided by UU. In Team B, the SSE students displayed good knowledge about the popularly used communication facilities, but UU students didn't show any superiority in using communication facilities 
provided by UU. In Team C, neither the SSE nor UU students demonstrated any knowledge on any communication facilities.

\section{5) Procrastination}

Face to Face Teams: Procrastination was well avoided.

Runestone Project: Teams: Team A didn’t have any procrastination. Team B didn't display any personal procrastination, but the team decided in the last minutes. Team C had severe personal procrastinations.

\section{6) Motivations in working}

Face to Face Teams: Motivations for participating were the same for SSE and Western students. Both of them liked to work with students from the other culture. Chinese students also wished to improve their English communication skills.

Some Western students thought that Chinese students had a very strong sense of competing with other teams.

Runestone Teams: SSE students were motivated by the reasons below to participate in Runestone: gaining global working experience, improving the skill of English communication, being attracted by robot programming, and getting enough credits for the degree because Runestone was the only course they could take at that moment.

The motivations for conducting good work were various from team to team. Team A was serious about everything and intensively worked on the challenge posed by the excellent parts of the design. Team B seemed to be enjoying the work more than concerned about the result. Team $\mathbf{C}$ displayed high ambitions at the initial phase but lost these ambitions when they really started working.

The SSE students usually prudently suggested focusing on the basic part of the design first of all. They seemingly lost their higher ambitions in the face to face teams, though they were quite cooperative in working on the excellent parts.

\section{7) Some supplementary observations}

The UU students displayed a strong sense of "fair play", and this sense played an important role in workload, role assignment, and chances of contributing to decision. In Team A, the SSE students thought that some UU members were dominating. Nonetheless it was observed that the decisions were made by voting, and the work was distributed evenly between two sub-teams in a sequential pattern. They also thought that both sides were aggressive in the sessions. In Team B, everybody was assigned a role. At the beginning every member did the same tasks and the best result was chosen as the solution. Later they distributed tasks evenly. In Team C, the work was distributed evenly, but the majority of members failed in fulfilling the distributed work.

\section{B. Comparisons made between Sino-Swedish and UU-GVSU Teams}

The aim of making these comparisons is to check the influences of the team members' cultural backgrounds.

\section{1) Communication}

UU-GVSU: Somebody failed to respond to email messages in a timely fashion; IRC missed subtle social information; one person spoke for the rest of the sub-team.
UU-SSE: SSE students complained about unreliable communication conditions. Only Team A was concerned about the social aspects of communication.

\section{2) Membership}

UU-GVSU: No participation or over participation.

UU-SSE: Over participation didn't occur in any team. No participation was only observed in Team C.

3) Leadership

UU-GVSU: Team leaders failed to keep people on task and were negligent in communicating deadlines and changes to requirement specifications.

UU-SSE: In Team A and Team B, a team leader was considered a communicator, and the team leaders were not resented for their insufficient work. Team $\mathbf{C}$ has the same problem as UU-GVSU team.

4) Technical issues

UU-GVSU: The insufficiency of working skills was displayed due to the members' different education backgrounds.

UU-SSE: The SSE students felt unconfident about their programming skills and their knowledge about the available communication facilities at UU.

\section{5) Procrastination}

UU-GVSU: Procrastination "is a golden oldie", causing not only frustration among team members but also lessening the degree of trust.

UU-SSE: only team C had the same problem as the UUGVSU teams.

\section{6) Motivation}

UU-GVSU: It was disturbing that some members did not seem motivated to try for extra points.

UU-SSE: No such problem was observed, though the SSE students were more concerned about completing the basic part of the project work due to their prudence.

\section{REFLECTIONS}

In this section, the special challenges and their impacts on the performances of the Sino-Swedish Runestone teams are summarized.

\section{A. Special Challenges from Computer Mediated Communication}

Like any globally distributed teams, the communication in the Sino-Swedish Runestone teams relied on computer mediated communication (CMC). CMC imposed the special challenges for the members, and the members had to adapt to these challenges.

\section{1) Constraints imposed by computer mediated} Communication

a) Synchronizing communication was limited by communication conditions: The qualities of communication facilities and the different time zones determined the qualities, lengths, and schedules of the sessions. 
b) Helpful communication strategies were invalidated: the effective strateties developed in the cross cultural face to face teams for enhancing the communication between SSE and Western students were no longer applicable.

c) Social information was restricted: Some researchers believe that CMC stripped off the personal and social information [7] in communication, while others argue that CMC can deliver the social information [8]. In the SinoSwedish Runestone teams, CMC evidently inhibited the members to address and perceive their social and personal information, because the main approach of communication for decision making is synchronous IRC, the sessions were limited in short time, and the latencies of getting responses were huge.

\section{2) Challenges from computer mediated communication}

a) Weakened membership: The membership in the SinoSwedish Runestone teams became weakened compared with that in the cross cultural face to face teams. In Team A, the trust was not actively built. The team worked effectively because they followed the principles of fair play and strict rules. Team $\mathrm{C}$ believed no need for all members to participate in the sessions.

b) Collaborative techonology usage: The ability of configuring and using collaborative technology is crucial for the funtionality of team work. By examining the performances of Team A, Team B, and Team C, it can be seen that good performance was proportional to how well the members configured and used collaboration technologies to share information.

c) The unknowable other side: Like a curtain, CMC made two sub-teams invisible to each other in many aspects. This uncertainty about the counterpart made the members unconfident in overcoming difficulties. For example, the SSE students felt unconfident about their Java programming skills and lack of the knowledge about the available collaborative technology provided by UU, though they have been exoeruenced in "learning and doing". The UU students asked the SSE students to contact the instructor from SSE.

\section{3) The Students' Adaptations}

Some adaptations toward CMC had been demonstrated by the Sino-Swedish teams.

a) Understanding importance of communication: The majority of the Sino-Swedish teams spotted the important role of communication in their work. Team A put configuring collaborative technology for sharing information in the highest priority. Team A and Team B interpreted the duty of the leader as communicator.

b) Making effective communications: Team A developed several strategies to make long and intensive sessions while reducing the frequency of sessions. Team A turned out to be the the most effective team. This result was in accordance with the outcomes of the research on Runestone teams in 2000, conducted by Hause et al.[9] .

c) Moving toward collaboration: Waite et al. [10] summarize four tactics used by students in their collaboration. The tactics are sequential segmentation, parallel segmentation, natural selection, and collaboration. The first three cases are considered as individual work. Team A adopted sequential segmentation. Team B at the beginning took natural selection but later switched to parallel segmentation. Team $\mathrm{C}$ took the approach of parallel segmentation. Team A and Team B posted the products from individual work for the members' comments and advice. They didn't simply divide and assemble the work, but moved toward collaboration.

\section{B. Challenges from Members' Cultural Backgrounds}

The members' sharply contrasting cultural backgrounds in the Sino-Swedish Runestone teams raised challenges in their collaboration.

\section{1) Shallow Collaborations}

Team A reached agreements by voting rather than reasoning and negotiating, although it was the most effective team. In addition, no effort for developing understanding and trust was observed in this team. Team B displayed trust, but its work wasn't effective.

In the UU-GVSU (Western-Western) teams, one of the communication problems was that one person collectively spoke for others. This wasn't observed in the Sino-Swedish Runestone teams. This fact might imply that the communication between Sino-Swedish members was so difficult that nobody was confident or comfortable enough to be dominating. The collaborations existing in the Sino-Swedish Runstone teams were shallow.

\section{2) Lack of social sensitivities}

The members in the UU - GVSU teams complained that IRC filtered out subtle social and personal information in communication. The majority of the SSE students didn't have this problem.

Team A was the only team that noticed the problem related to the social activities. They noticed that the UU students in the team were dominating, and felt uneasy about the aggressive manners displayed by both sides. Only one SSE student from Team A complained about the problem presented by the UUGVSU teams. The SSE students in Team A were highly experienced in cross cultural collaboration and spoke very good English.

\section{CONCLUSION}

The special challenges encountered by the members in the Sino-Swedish Runestone teams derived from CMC and the members' sharply contrasting cultural backgrounds. These teams, particularly Team A, managed to make certain adaptations toward CMC. However, they were not able to deal with the cultural challenges. In this section, some tips for working in globally distributed environments are suggested. In addition, the puzzling cultural challenges are raised as possible research topics.

\section{A. Some Practical Tips}

Based on the challenges from CMC and the members' adaptations to CMC, the tips below are suggested.

1) Making students strongly aware of sharing information 
The students should be conscious about the importance of sharing information among the members of the team. They should configure the suitable collaborative technology for sharing information as early as possible, and update the shared information in a timely manner. Keeping good communication should be the central duty of the team leader. Making clear and practical rules.

The shared information should be addressed explicitly The rules and working procedures should be clearly defined and strictly followed.

\section{2) Prepare the the students for the Runestone Project}

The students should be well prepared before they participate in the Runestone project. They should equip themselves with the necessary knowledge and skills for developing software systems and gain wide knowledge about the commonly used collaborative technology. It is most important to make sure that the participants know the available communication facilities provided by the UU (the host university) well.

\section{3) Making long and sufficient sessions}

The students should make long and effective sessions and reduce the frequency of sessions.

\section{B. Some Possible Research areas}

The cultural challenges are hard to understand. In addition, CMC and the members' cultural backgrounds don't work respectively, but mutually impact. The following research topics are raised in the aim of understanding the challenges and figuring out the measures to deal with the challenges.

1) How to develop students' cutltural and social sensitivities in the Runestone project?

It has been discussed that CMC in the Sino-Swedish teams filtered off the social and personal information. However, the cultural and social sensitivities are necessary for effective collaboration.

2) What level of trust makes for ideal collaboration in the Runestone project?

Team A had low trust but high performance, while Team B had high trust but low performance, and Team $\mathrm{C}$ had low trust and low performance. What is the ideal collaboration in CMC environments and the role of trust in how to achieve the collaboration should be answered.
3) What constraints are imposed by CMC and how the students from different cultural backgrounds adapt to the constraints?

The advantages of different cultural backgrounds in collaboration observed in the cross cultural face to face teams were absent in the Sino-Swedish Runestone teams. The insights on constraints caused by CMC and the members' responses to the constraints in the cultural dimensions will help to improve collaboration in these teams.

\section{ACKNOWLEDGMENT}

The thanks go to all students and instructors for sharing their thoughts and ideas. The most cordial thanks are due to Dr. Anders Berglund. He initialized the Runestone project between Uppsala University and Tongji University. In addition, some ideas about the cross cultural face to face teams used in the paper were from our formerly collaborative work.

\section{REFERENCES}

[1] M. Hawthorne and D. Perry, "Software Engineering Education in the Era of Outsourcing, Distributed Development, and Open Source Software: Challenges and Opportunities," in Software Engineering Education in the Modern Age. vol. 4309, P. Inverardi and M. Jazayeri, Eds., ed: Springer Berlin Heidelberg, 2006, pp. 166-185.

[2] T. L. Friedman, The World Is Flat: A Brief History of the Twenty-first Century. Farrar, Straus and Giroux, 2007.

[3] F. Huang, "Policy and Practice of the Internationalization of Higher Education in China," Journal of Studies in International Education, vol. 7, pp. 225-240, September 1, 2003.

[4] MoE. (2001). Document of China's Education Ministry No 32001. Available: http://rjb.bjtu.edu.cn/show.php?id=39M.

[5] A. Pears and M. Daniels, "Developing global teamwork skills: The Runestone project," in Education Engineering (EDUCON), 2010 IEEE, 2010, pp. 1051-1056.

[6] M. Z. Last, M. Daniels, V. L. Almstrum, C. Erickson, and B. Klein, "An international student/faculty collaboration: the Runestone project," SIGCSE Bull., vol. 32, pp. 128-131, 2000.

[7] T. Connolly, L. M. Jessup, and J. S. Valacich, "Effects of Anonymity and Evaluative Tone on Idea Generation in Computer-Mediated Groups," Management Science, vol. 36, pp. 689-703, June 1, 1990.

[8] J. B. Walther, "Group and Interpersonal Effects in International Computer-Mediated Collaboration," Human Communication Research, vol. 23, pp. 342-369, 1997.

[9] M. Hause, M. Petre, and M. Woodroff, "Performance in international computer science collaboration between distributed student teams," in Frontiers in Education, 2003. FIE 2003 33rd Annual, 2003, pp. S1F-1318 vol.3.

[10] W. M. Waite, M. H. Jackson, A. Diwan, and P. M. Leonardi, "Student culture vs group work in computer science," presented at the Proceedings of the 35th SIGCSE technical symposium on Computer science education, Norfolk, Virginia, USA, 2004. 